\title{
São Miguel Paulista dos "baianos"
}

\author{
Paulo Fontes:
}

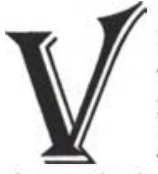

ilarejo de Caem, município de Jacobina, interior da Bahia, dezembro de 1947. Ansioso, Artur Pinto de Oliveira despede-se da família e deixa para trás a casa e o sítio onde vivera seus primeiros 17 anos de vida. O rapaz, cheio de esperanças de uma vida melhor e com "aquele sonho de estudar na cabeça", contaminara-se com a "febre da época": São Paulo. "Naquele tempo todo nordestino sonhava em vir para São Paulo. São Paulo virou o céu, era o paraíso", relembra mais de 50 anos depois.

Artur seguia os passos de um irmão mais velho, que se mudara alguns meses antes e já estava trabalhando como operário na Cia. Nitro Química Brasileira. Intensa correspondência entre ele e a família demovera as resistências do pai em permitir que seu outro filho também seguisse para a capital paulista. Naquele dia no final dos anos 40, Artur juntou seus parcos pertences e partiu para uma longa jornada.

A viagem, de fato, era longa e extenuante. Da sede do município em Jacobina, ele tomou um trem até Juazeiro. De lá, atravessou o rio e na vizinha cidade de Petrolina, já no estado de Pernambuco, comprou a passagem mais barata e embarcou no vapor que descia o rio São Francisco até a cidade mineira de Pirapora. Foram 15 demorados dias de viagem. $\mathrm{O}$ período de seca no interior nordestino exigia que o barco fosse conduzido vagarosamente para não encalhar nas areias do rio.

Juntamente com outras centenas de migrantes, Artur espremia-se na segunda classe do barco localizada no porão. Aquilo "era como um navio negreiro dos escravos africanos" comparou, "você não via nada. Cheio de gente, uma promiscuidade danada, uma escuridão, um mau cheiro...".
A viagem só não foi pior porque Artur, conversador, fez amizade com "um senhor de Goiás, uma pessoa formada, muito educada e comunicativa" e passou aqueles dias discutindo "porque o Nordeste era paupérrimo e as pessoas todas migravam para outras regiões". Mesmo tão jovem, Artur já tinha as suas "teses de achar o porque que não se resolvia os casos no Nordeste" e propunha o aproveitamento das águas do São Francisco e do Amazonas para um amplo sistema de irrigação na região.

Provavelmente seduzido pela curiosidade do menino, o goiano afeiçoou-se de Artur e convidava-o periodicamente para almoçar no restaurante da primeira classe. Chegados em Pirapora, despediram-se. Um rumando para Goiás e o outro para sua nova vida mais ao sul do país. De Pirapora para São Paulo foram mais três dias de viagem de trem. No início de janeiro de 1948, Artur desembarcava na famosa estação do norte no bairro paulistano do Brás. De lá, mais um trem, e finalmente chegava ao seu destino, São Miguel Paulista, onde "não tinha uma rua sequer asfaltada". Era ali que Artur trabalharia por mais de 40 anos e tem morado toda a sua vida.'

Também em 1948, Augusto Ferreira Lima deixou sua terra natal. Filho de um pequeno proprietário que vivia de suas plantações de laranjas em Alagoinhas, agreste baiano, Augusto, aos 25 anos, decidira que era hora de tentar a sorte no Sul.

Desde criança trabalhando no laranjal da família, Lima, aos dezesseis anos empregou-se na Ferrovia Leste Brasileiro. Por dois anos, dividiu seu tempo entre a plantação e a colocação de dormentes na construção e manutenção da linha férrea. Mais tarde, aprendeu o serviço de topógrafo e por mais sete anos continuou a trabalhar na roça e na ferrovia.

Ir para São Paulo, no entanto, era desejo antigo. A vontade era reforçada periodicamente pelas visitas de conhecidos que voltavam para rever as famílias no interior da Bahia. Lima recorda-se que era um acontecimento ver "chegar um baiano (...) metido num terno bacana e gravata. Naquele tempo [em São Paulo], tinha que usar mesmo". Aquilo chamava a atenção das "garotas, enquanto nós, lá, tínhamos que sair naquela roupinha. Isso aí trouxe um bocado de vontade humana do caboclo correr para São Paulo". As histórias sobre a cidade, sua grandiosidade, a abundância de trabalho, as opções de lazer, tudo isso também seduzia Lima. Lembra-se como hoje de um conhecido, de nome Evelino, contando as excursões para Santos, da bela viagem de trem pela Serra do Mar. A primeira vez que tirou férias, já em São Paulo, Augusto Lima repetiria Evelino e passearia de trem para o litoral santista.

Com o dinheiro economizado do salário na ferrovia, Lima comprou sua passagem para São Paulo. Era um caminhão, o famoso pau-de-arara. De tão lotado, foi necessário amarrar três tábuas para fora do veículo. E foi assim que, durante 11 dias, viajou para a capital paulista.

Vindo pela estrada Rio-São Paulo, a única existente à época, a primeira parada na cidade era na igreja de São Miguel Paulista. Tendo um conhecido na região, com o qual havia mantido contato, Lima pegou sua "mala de papelão", jogou seu "patuá nas costas" e desceu ali mesmo. Pisava pela primeira vez no bairro onde moraria desde então, vislumbrando ao longe as chaminés da Nitro Química, fábrica onde trabalharia durante os 37 anos seguin- 
tes. ${ }^{2}$

As trajetórias de Artur e Augusto não são incomuns. Na verdade, são relatos paradigmáticos de experiências similares de milhões de brasileiros e brasileiras. A grande migração de trabalhadores das regiões rurais para as cidades é um dos fatos marcantes da história social brasileira na segunda metade do século XX. Entre 1950 e 1980, estima-se que mais de 38 milhões de pessoas saíram do campo, alterando profundamente o perfil sócio-econômico do país (Hasenbalg, 1991, p. 9). ${ }^{3}$

A região metropolitana de São Paulo (como principal receptora) e o Nordeste (como região de origem de grande parte dos migrantes) possuem papel central nesse processo. ${ }^{4} \mathrm{~A}$ figura do trabalhador nordestino escapando da fome, miséria e, periodicamente, das secas chegando à metrópole industrial em busca de emprego e melhores condições de vida tornou-se um símbolo da migração no imaginário social brasileiro. São Paulo transformou-se no local de moradia e emprego para milhões de nordestinos. A velocidade desse processo impressiona. Nos 20 anos que separam 1950 de 1970, a cidade triplicou seu tamanho enquanto que, no mesmo período, a população de origem nordestina cresceu dez vezes (Weffort, 1988).

$\mathrm{Se}$, de um lado, é inegável que tais migrações internas tornaram-se objeto largamente estudado nas instituições governamentais e universidades, particularmente no final dos anos 60 e durante os 70 , por outro a análise específica das influências do processo migratório na formação da classe trabalhadora brasileira ainda carece de maior pesquisa e sistematização, em que pese as iniciativas pioneiras de sociólogos do trabalho durante os anos 50 e 60 (Hasenbalg, 1991).

Partindo do estudo de caso do bairro paulistano de São Miguel Paulista e da Nitro Química, grande fábrica ali localizada, esse artigo é parte de uma pesquisa de maior fôlego que, justamente, procura explorar as relações entre as tradições e costumes dos migrantes nordestinos de origem rural e o processo de formação da classe trabalhadora em São Paulo, particularmente nos anos 50. São Miguel Paulista e a Nitro Química são lugares particularmente interessantes para examinar essa questão. A grande maioria das operárias e operários da empresa era composta de migrantes nordestinos e, em conseqüência, São Miguel Paulista tornou-se (e é até hoje conhecido como) o primeiro "bairro nordestino" da capital paulista.

\section{'SÃO MIGUEL, O NORDESTE EM SÃo PAULO'}

A história do bairro paulistano de São Miguel Paulista foi alterada profundamente nos anos 30, quando ali se instalou a Companhia Nitro Química Brasileira. Aldeamento indígena e missão jesuíta nos séculos 16 e 17, a região, embora um dos mais antigos bairros da cidade de São Paulo, pouco se desenvolveu nos séculos seguintes, permanecendo como um pequeno núcleo habitacional no extremo leste do município.

Seduzidos pelo baixo custo dos terrenos, pela proximidade de uma estação ferroviária e de grandes reservatórios de água do rio Tiête, os empresários José Ermírio de Moraes e Horácio Lafer viram no bairro a localidade ideal para a instalação da grande fábrica química que haviam acabado de adquirir nos Estados Unidos. Com o generoso apoio do governo Vargas, mais de 18 mil toneladas de equipamentos e maquinaria foram transferidas da fábrica original na Virgínia para São Miguel. Em 1937, após dois anos de construções e instalações, a fábrica iniciou seu funcionamento.

A Segunda Guerra Mundial traria uma grande expansão para os negócios da empresa. Apoiada na fabricação de raiom, fio artificial largamente utilizado na indústria têxtil de então, a Nitro Química transformou-se na maior produtora de raiom do país. Em 1946, com mais de 4 mil operários e operárias, a empresa era uma das maiores indústrias paulistanas e uma das mais lucrativas companhias do Brasil (Telles, 1981, p.31).

Nesse período, um ambicioso plano de expansão econômica foi elaborado pelos dirigentes da empresa. Seu objetivo era tornar a companhia a "CSN do setor químico", ou seja, a grande fábrica nacional de base deste ramo industrial. Os anos 50 foram, então, marcados por grandes inves- timentos na produção e pela ampliação do serviço social, setor responsável pela assistência aos trabalhadores e seus dependentes nas áreas de saúde, moradia, alimentação e lazer, considerado por muitos como exemplar no país. Tal projeto, entretanto, fracassou e em finais dos anos 50, a Nitro Química iniciaria um longo processo de decadência econômica (Fontes, 1997).

Ao longo dos anos 40 e 50 , porém, milhares de trabalhadores migrantes do interior de São Paulo, Minas Gerais e, principalmente, do Nordeste foram atraídos pela grande quantidade de empregos oferecidos pela empresa. São Miguel Paulista passou a ter um vertiginoso crescimento, tornando-se uma das regiões com maior incremento populacional da cidade. Com não mais de 4 mil moradores em meados dos anos 30, o bairro contava com cerca de 105 mil em 1957(Azevedo, 1958 e Arantes Neto, 1978, p. 12). Em 1980, o censo apontava 320 mil habitantes.

A predominância de migrantes nordestinos fez a fama do bairro desde os anos 40. Conhecido como "Bahia Nova", a região consolidou-se como um dos principais locais de moradia dos nordestinos na cidade até os dias de hoje. Em uma matéria sobre a história do bairro redigida em meados dos anos 80 , um jornalista relata que "ao andar em certos pontos de São Miguel o visitante sente-se como se estivesse no Nordeste". "As 'casas do norte' proliferam", prosseguia o repórter, e "ainda se vêem grupos de forró tocando em bares e barbearias". São Miguel Paulista "é uma verdadeira capital nordestina", concluía, lembrando que dentre os "moradores do bairro, $80 \%$ vieram do Nordeste" (Nascimento, 1987).

Certamente todo o assombroso crescimento do bairro e sua identificação com a migração nordestina em São Paulo não pode ser somente atribuído à instalação da Nitro Química. A expansão de São Miguel deve ser associada ao crescimento da cidade de São Paulo como um todo. A ampla oferta de terrenos e o intenso processo de loteamentos desenvolvido no bairro a partir dos anos 40 possibilitava a muitos migrantes o relativamente fácil acesso à moradia mais barata e própria.

A partir de meados dos anos 40, a questão da habitação era um grande problema 
para os trabalhadores em geral, e particularmente para os recém-chegados a São Paulo. A escassez de residências e o incremento dos aluguéis nas regiões centrais da cidade obrigavam grande parte da população pobre a instalar-se em regiões cada vez mais afastadas e com poucos recursos. $\mathrm{O}$ grande influxo migratório nos anos 50 acelerou ainda mais a criação de distritos e bairros na periferia da cidade.

Para a maioria dos trabalhadores, a possibilidade da casa própria em São Paulo somente podia ser realizada através da autoconstrução da moradia em lotes periféricos adquiridos à prestação e desprovidos de toda infra-estrutura. Esse "padrão periférico de crescimento urbano" (Kowarick e Bonduki, 1988; Sader, 1988; Bógus, 1992), marcou o desenvolvimento da cidade entre os anos 40 e 80.

São Miguel Paulista foi um dos principais bairros onde tal tipo de crescimento ocorreu. Inúmeros loteamentos transformaram-se em distritos e vilas com pouca ou quase nenhuma infra-estrutura urbana e com residências construídas, no mais das vezes, pelos próprios moradores. Entretan- to, a existência de uma grande indústria proporcionava características distintas ao bairro. Entre o final dos anos 30 e o início dos 60, a Nitro Química foi a maior provedora de empregos na região. Ao contrário de outros distritos periféricos, desde sempre considerados como "bairros-dormitório", São Miguel nesse período possuía caraterísticas de uma verdadeira cidade industrial dentro do município de São Paulo.

Assim, por exemplo, grandes deslocamentos em transporte coletivo, um dos principais problemas dos trabalhadores em São Paulo já nos anos 50, eram evitados e a possibilidade de trabalhar perto da moradia era vista, portanto, como uma grande vantagem pelos habitantes de São Miguel, região distante cerca de 35 quilômetros do centro da cidade.

No entanto, o contínuo crescimento da população residente e a decadência da indústria alteraram essa situação. Se a Nitro Química ainda possuía uma grande importância simbólica e histórica para o bairro, do ponto de vista econômico e da geração de empregos, seu papel foi cada vez me- nor desde meados dos anos 60. São Miguel Paulista, porém, ainda continuaria atraindo nordestinos em novas levas migratórias ao longo das décadas de 70 e 80 .

\section{BERÇO DOS NORDESTINOS}

Grande parte das análises sobre a migração dos trabalhadores rurais nordestinos para São Paulo e outras cidades industriais do Sudeste brasileiro enfatizou as motivações econômicas desse processo. De acordo com essa visão, a situação de miséria no campo, a concentração fundiária e o avanço do latifúndio sobre as terras dos pequenos proprietários, assim como as alterações das relações de trabalho, o alto índice de crescimento demográfico nordestino e as periódicas secas seriam alguns dos fatores que imporiam a migração como última saída ao trabalhador rural. Este, por sua vez, atraído pelos empregos e maiores rendimentos da vida urbana, pela possibilidade de acesso aos direitos sociais e trabalhistas negados no campo, bem como pela maior oferta de educação e saúde, tornaria-se proletário, preenchendo, dessa

Foto: Biblioteca Adelço de Almeida do Sindicato dos Químicos e Plásticos de São Paulo.

Operários-Migrantes da Nitroquímica / São Miguel Paulista, Anos 40

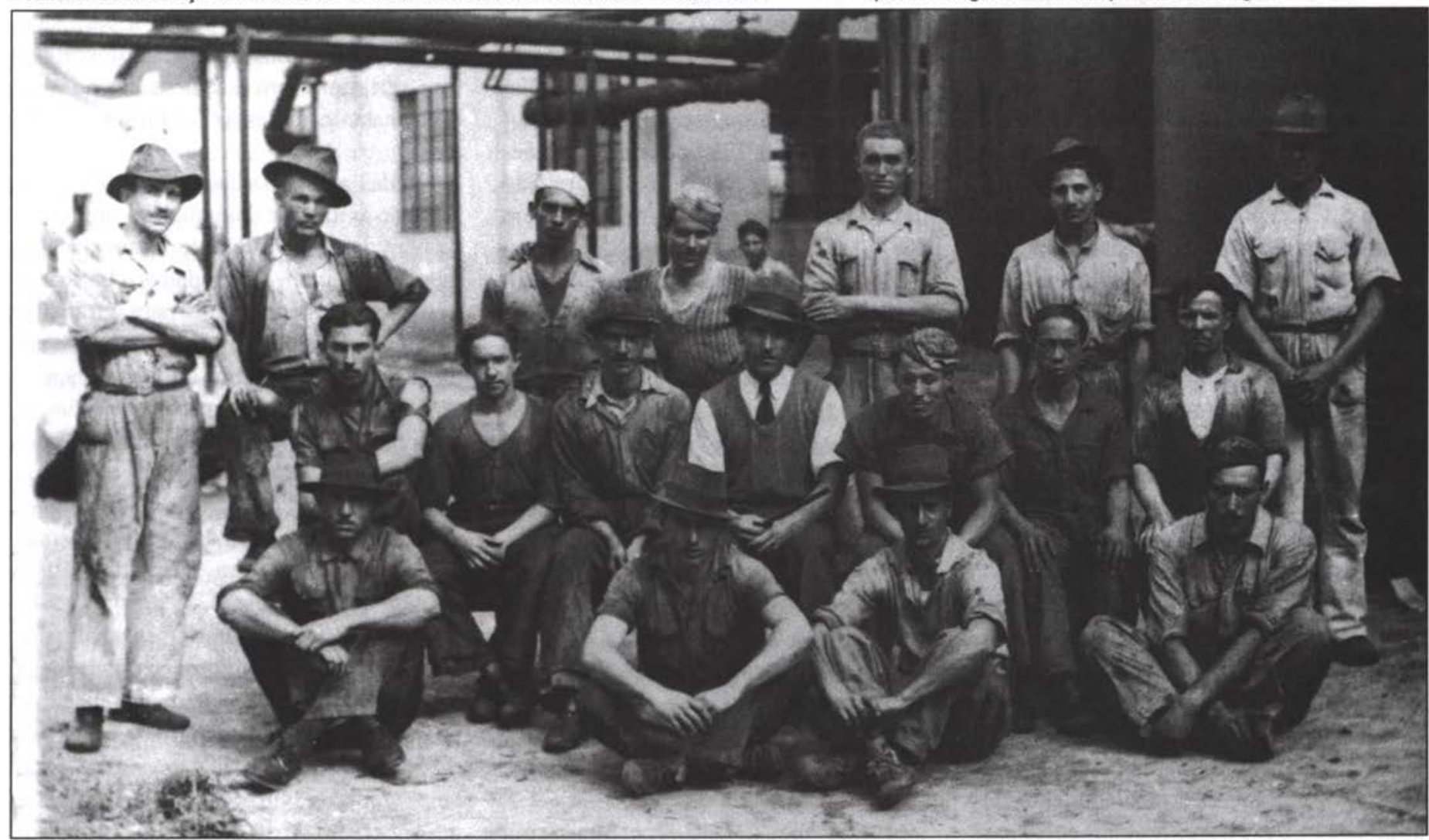


forma, a demanda por mão-de-obra do processo de industrialização.

Não há dúvidas sobre a importância desse quadro sócio-econômico como pano de fundo do processo migratório e do desenvolvimento capitalista brasileiro. Entretanto, a supervalorização dos fatores econômicos acaba por perder de vista o papel dos próprios migrantes enquanto agentes envolvidos nesse processo. Em muitos desses estudos os migrantes são vistos apenas como cifras, como força de trabalho que se transfere passivamente das regiões menos para as mais desenvolvidas.

Os migrantes rurais nordestinos não eram apenas reflexo de forças econômicas determinadas externamente, embora estivessem imersos nelas. Eles também foram agentes do seu próprio movimento e dessa forma, através de estratégias diversas, contribuíram na moldagem do processo migratório.

Os depoimentos das trabalhadoras $\mathrm{e}$ trabalhadores de São Miguel Paulista nos revelam a existência de uma articulada rede social para a efetivação da migração. A comunidade de origem, a família e os amigos e amigas desempenhavam papel determinante nessa rede. Dona Zezé Santos de Oliveira, por exemplo, chefe do correio local durante mais de trinta anos entre as décadas de 40 e 70 , notava que entre as centenas de pessoas que todos os dias desembarcavam dos paus-de-arara na frente do posto do correio, "ninguém vinha aereamente. Vinha porque o compadre estava [morando no bairro]". Augusto Lima, relatando a sua própria chegada em São Miguel Paulista, recorda-se que "quem tinha conhecido por aqui descia e procurava a casa de seus amigos". 5

Uma certa imagem da migração, vista como um movimento desordenado, 'irracional', feito às pressas, não corresponde à experiência da maior parte dos migrantes. A mudança, decisiva para a vida dos envolvidos, era, na maior parte das vezes, meticulosamente pensada e preparada da melhor forma possível tanto no âmbito familiar como no da comunidade.

Informações sobre São Paulo, suas oportunidades de emprego e possibilidades de moradia eram fundamentais para a decisão de migrar. $\mathrm{O}$ estabelecimento de uma rede de comunicação entre os migrantes e seus locais de origem freqüentemente orientava o processo migratório. Correspondências, fotos, cartõespostais tinham papel importante para o fornecimento de dados e criação de um "imaginário cultural do local de destino" (Thomson, 1999, p.28). Irene Ramalho, adolescente no interior de Minas Gerais, lembra-se que sonhava dia e noite com São Paulo porque "eu tinha os meus irmãos morando aqui em São Miguel, e eles escreviam as cartas para nós lá". Geraldo Rodrigues de Freitas, já trabalhando em Santos, decidiu mudar-se para a capital paulista no final dos anos 40 pois "tinha uma pessoa conhecida aqui [em São Miguel] e ele escreveu para mim (...) [dizendo] que eu tinha emprego garantido na Nitro". "Sempre tinha um amigo que escrevia e encontrava", acrescenta Augusto Lima. $^{6}$

Também a visita de trabalhadores a seus parentes e amigos no interior nordestino, além de acirrar o desejo de migrar entre os mais jovens e aqueles que haviam ficado, era uma ocasião importante para troca de experiências e possíveis planejamentos de novas migrações. Foi o caso de Afonso José da Silva que, acompanhado do "tio Fernando, (...) guarda na Nitro Química" e do primo Zacaria, que também trabalhava na fábrica e "falava que [São Miguel] era bom, que se ganhava dinheiro", além de mais 12 conterrâneos de Senhor do Bonfim, Bahia, veio para São Miguel Paulista aos 20 anos de idade em 1948. ${ }^{7}$

Movimentos migratórios não eram novidade para um grande contigente de famílias nordestinas. Migrações sazonais do sertão e do agreste para o corte de cana de açúcar na zona da mata eram constatadas desde antes dos anos 30 (Andrade, $1964 \mathrm{e}$ Menezes, 1999, p.7). Transferências temporárias ou definitivas do campo para pequenas e médias cidades e migrações regionais no interior do próprio Nordeste também eram comuns. No entanto, a distância e o tamanho da empreitada que a mudança para São Paulo implicava exigiam uma boa articulação e preparação em relação ao passo a ser dado. A família e as relações sociais na comunidade de origem tinham importância central neste processo.

Muitas vezes, isso significava um fracionamento provisório da unidade familiar. O risco envolvido na migração, particularmente a de longa distância, impunha uma estratégia de deslocamento parcelado por parte das famílias migrantes (Durham, 1976). Em geral, os jovens solteiros iniciavam o processo ancorados freqüentemente em contatos com amigos, conterrâneos ou parentes distantes. Quando haviam oportunidades, a possibilidade de migração para cidades menores ou para regiões agrícolas antes de uma possível vinda para São Paulo era sempre levada em conta. Esse 'estágio' no processo migratório era considerado como mais uma alternativa ao risco e insegurança que a vinda direta poderia significar (Almeida e Mendes Sobrinho, 1951, p.27).

Migrações temporárias faziam parte das estratégias de obtenção de recursos de milhares de famílias nordestinas (Scott, 1986). As primeiras gerações de migrantes em São Paulo possuíam alta mobilidade espacial. Para muitos, provavelmente a maioria, a mudança era vista como algo provisório, parte de um plano de sobrevivência e ascensão familiar. Daí as altas taxas de retorno. No final da década de 50, cogitava-se que cerca da metade dos migrantes nordestinos voltava para suas regiōes de origem. Alguns estudiosos, porém, questionavam essa taxa, considerando-a bastante modesta (Fischlowitz, 1959. p. 97),

Redes sociais baseadas na família e nos laços de amizade e comunitários eram fundamentais para o migrante. Eram elas que o encaminhavam para cidades e bairros, e muitas vezes, diretamente para o trabalho em empresas específicas. Era esse o caso em São Miguel Paulista e na Nitro Química.

Em seus primeiros anos de existência, $o$ agenciamento de trabalhadores no interior de São Paulo e do Nordeste foi uma estratégia usada pela Nitro Química para a arregimentação de mão-de-obra. A partir dos anos 40 , porém, tal prática já não era tão comum (Fontes, 1997, pp.79-84). Os próprios contatos entre os trabalhadores e seus parentes, amigos e conterrâneos passaram a desempenhar um papel decisivo na composição do quadro de funcionários da empresa. Oscar Alonso de Souza, empregado na Nitro entre 1954 e 1993 e um dos chefes do departamento pessoal du- 
rante grande parte desse período, explica assim a grande presença nordestina em São Miguel Paulista:

"Como é que vinha do Nordeste? (...) é fato que veio nordestino para cá (...). Vinha e arrumava uma colocação na Nitro Química porque alguém indicou. Por sua vez ele procurava trazer um parente, pai, mãe, irmão, amigo, enfim... E assim foi crescendo a comunidade nordestina aqui na região". 8

A fama da Nitro Química como uma empresa "boa de dar emprego" e que proporcionava uma série de "benefícios sociais" era certamente um grande fator de atração. "A gente vinha aqui porque essa fábrica aí pegava muita gente", explica Gerolino Costa Jacobina.' De fato, a grande maioria dos depoimentos destaca a facilidade em conseguir trabalho e a rapidez na contratação. Augusto Lima lembra-se que:

"Era só você descer para lá e passar na portaria. Cheguei, encostei na portaria, dentro de cinco minutos a turma falou: 'Oh, conterrâneo, (...) quer trabalhar, encosta'. Naquele tempo, (...) era [direto] para a produção". ${ }^{10}$

Esse quadro de abundância de trabalho era reforçado pela idéia de que a empresa beneficiava os migrantes, particularmente os nordestinos, na hora da contratação. "Pode entrar, vai trabalhar, nós queremos é baiano assim, novo, do sangue quente", teria dito o médico da companhia a Augusto Lima, logo após o exame que aprovou a sua contratação. "Aqui era um berço. A Nitro Química foi um berço dos nordestinos", atesta Afonso José da Silva."

Embora não formal, a política de contratação de parentes e de indicações dos empregados era estimulada pela própria empresa. Contribuía para a criação de laços de confiança e responsabilidade, reforçando o discurso patronal de constituição de uma "grande família nitrina" (Fontes, 1997). A empresa apostava no papel vigilante que familiares e amigos exerceriam um sobre os outros em caso de embates e conflitos no local de trabalho. ${ }^{12}$ Por fim, a imagem de companhia que ajudava os nordestinos migrantes e a conseqüente afluência de trabalhadores eram extremamente úteis para uma empresa com grande necessidade de mão-de-obra e, ao mes- mo tempo com altíssimas taxas de rotatividade no emprego. ${ }^{13}$

Entretanto, a contratação de parentes, amigos e conterrâneos podia muitas vezes significar a manutenção e o aprofundamento de lealdades e solidariedades em geral anteriores ao próprio emprego na Nitro Química. Freqüentemente tais relações chocavam-se com os interesses e desejos da empresa.

Para além da abundância de emprego e de seu sistema de benefícios, as péssimas condições de trabalho são outro forte elemento presente na memória dos trabalhadores de São Miguel. A imagem da Nitro Química é recorrentemente associada a acidentes e altos índices de insalubridade. Protestos e luta contra tal ambiente de trabalho foram constantes desde a sua fundação.

Acidentes, mutilações e mortes são unanimemente apontados pelos trabalhadores de diferentes gerações como suas piores recordações. Famoso pela insalubridade, o setor de fiação, onde eram produzidos os fios de raiom, era uma espécie de símbolo da precariedade das instalações da empresa. Um sistema de ventilação inadequado não conseguia dispersar os gases tóxicos formados no processo de manufatura do fio e contaminava os operários. Era para essa seção que a maioria dos novos contratados era enviada. "Pior seção da fábrica”, relembra José Cecílio Irmão. O operário "trabalhava dois, três dias. Enchia a cara de gás e ia para o seguro. Os olhos ficavam vermelhos. Você ficava maluco. (...) Você não agüenta. Usava colírio, batata (...) para refrescar". ${ }^{14}$

Roniwalter Jatobá, jornalista e escritor, morou em São Miguel Paulista no início dos anos 70, e em uma das suas crônicas, registrou assim a infelicidade de um operário do setor de fiação da Nitro Química:

"Segunda de noite, a fábrica: seção F5[fiação de raiom], Nitro Química, o gás rondando os olhos, entrando nas vistas marejadas, cegueira. A voz do feitor apressando (...) a dor nas vistas. (...) No rumo de casa, tateando pelas ruas, chegava, depois o bálsamo da batata crua sobre os olhos, sugando o gás, a verdura empretecendo" (Jatobá, 1988).

A periculosidade da fábrica era largamente conhecida em São Miguel. Quan- do, em junho de 1947, um reator na seção de trotil explodiu causando a morte reconhecida de nove operários, violeiros e poetas de cordel saíram pelas ruas e bares do bairro cantando a história da "terrível explosão que sacudiu a Nitro Química Brasileira" que ocorrera supostamente pela "manipulação de ácido em demasia". ${ }^{15}$ O temor de novas explosões e os cotidianos acidentes com vítimas, algumas vezes fatais, fazia parte do cotidiano dos operários e moradores. Quando a fábrica "tocava aqueles apitos curtos", recorda-se um morador do bairro, entrevistado no final dos anos 70, "a gente já sabia que era incêndio, então ficava todo mundo meio apavorado porque inclusive falaram que se a Nitro Química explodisse (...) a cidade inteira ia junto com a fábrica (...). Então todo mundo tinha medo, e houve acidentes graves aí. Eu conheci explosão [em que] faleceu o pai do nosso amigo... família Martins" (Arantes Neto, 1978, p.11). ${ }^{16}$

A despeito do serviço social e dos decantados benefícios da empresa, muitos trabalhadores avaliavam que aquelas condições de trabalho eram uma demonstração de como eles podiam ser descartáveis para a Nitro Química.

A suportabilidade de tal ambiente de trabalho dependia em grande medida da criação de padrões de sociabilidade que abrandassem a dureza do cotidiano da fábrica. A informalidade das relações entre os trabalhadores através de brincadeiras e jogos em meio à produção cumpriam um papel decisivo para uma "reinvenção criativa" do trabalho (Lopes, 1988, p.82). Brincadeiras parecem fazer parte da cultura do chão da fábrica. Paul Willis, em seu estudo sobre a cultura fabril em indústrias inglesas nos anos 70, observou entre os operários uma forte disposição para jogos e brincadeiras, particularmente os de caráter físico (Willis, 1979, p.193). Na Nitro Química, José Cecílio Irmão lembra que "tinha muita brincadeira (...). O peão não tem jeito, ele acha uma brecha para tudo. Mexia com o camarada, cutucava, enfim, batia, lutava boxe". Apelidos também eram freqüentes no chão da fábrica. José Ferreira da Silva, funcionário da companhia entre 1946 e 1966, conta que na seção onde trabalhava havia " 140 operários e quase todos tinham apelidos, até os 
chefes". ${ }^{17}$

As relações informais, base de várias práticas de solidariedade e auxílio mútuo entre os trabalhadores do campo e os migrantes, continuavam a ser fundamentais para os operários da Nitro Química. Os laços de parentesco e amizade, a procedência comum das mesmas regiões do interior do Nordeste e a concentração de moradias no mesmo bairro, assim como a experiência comum de migração e aprendizado sobre a nova cidade e o novo trabalho vivenciado nas mesmas duras e extenuantes condições foram fatores que possibilitaram a formação de uma extensa rede de convivência e sociabilidade entre os trabalhadores de São Miguel Paulista nos anos 40 e 50 .

As redes sociais eram consolidadas e ampliadas no interior da fábrica. Um trabalhador relata que na Nitro "tinha uma amizade boa, sadia. Eram todos amigos (...) cada um com seu apelido". Tais relações de amizade ultrapassavam os portões da empresa. Quando alguém contava no local de trabalho que:

"Ia matar um porco, quando a gente saía do serviço, acompanhava ele (...). Matava o porco, comprava a carne, pagava no pagamento. Ia na casa dele e comia. Tinha muito disso". ${ }^{\mathrm{x}}$

Estudiosos das primeiras gerações de migrantes que se tornaram operários em São Paulo questionaram a existência de ações coletivas no interior das empresas. Observaram a existência de vários grupos de amigos, que expressavam sua amizade em "conversas, caçoadas, brincadeiras de mão (...) e às vezes um convívio fora do recinto da fábrica". Tais relações de amizade seriam baseadas no convívio comum, em laços de parentesco ou pelo fato de serem originários da mesma cidade ou região. Isso se daria pela proveniência rural desse trabalhadores, "onde a oportunidade de participação em ação coletiva que existe é na base de laços de parentescos e de vizinhança" (Lopes, 1964, pp.57 e 69).

De acordo com essa visão, a persistência de tais vâlores no ambiente urbano prejudicaria a formação de laços comuns e ações organizadas que expressassem a formação de uma classe. Os trabalhadores se uniriam através de uma "forma de solidariedade afetiva e pessoal, e não o sentimen-

Foto: Biblioteca Adelço de Almeida / Sindicato dos Químicos e Plásticos de São Paulo

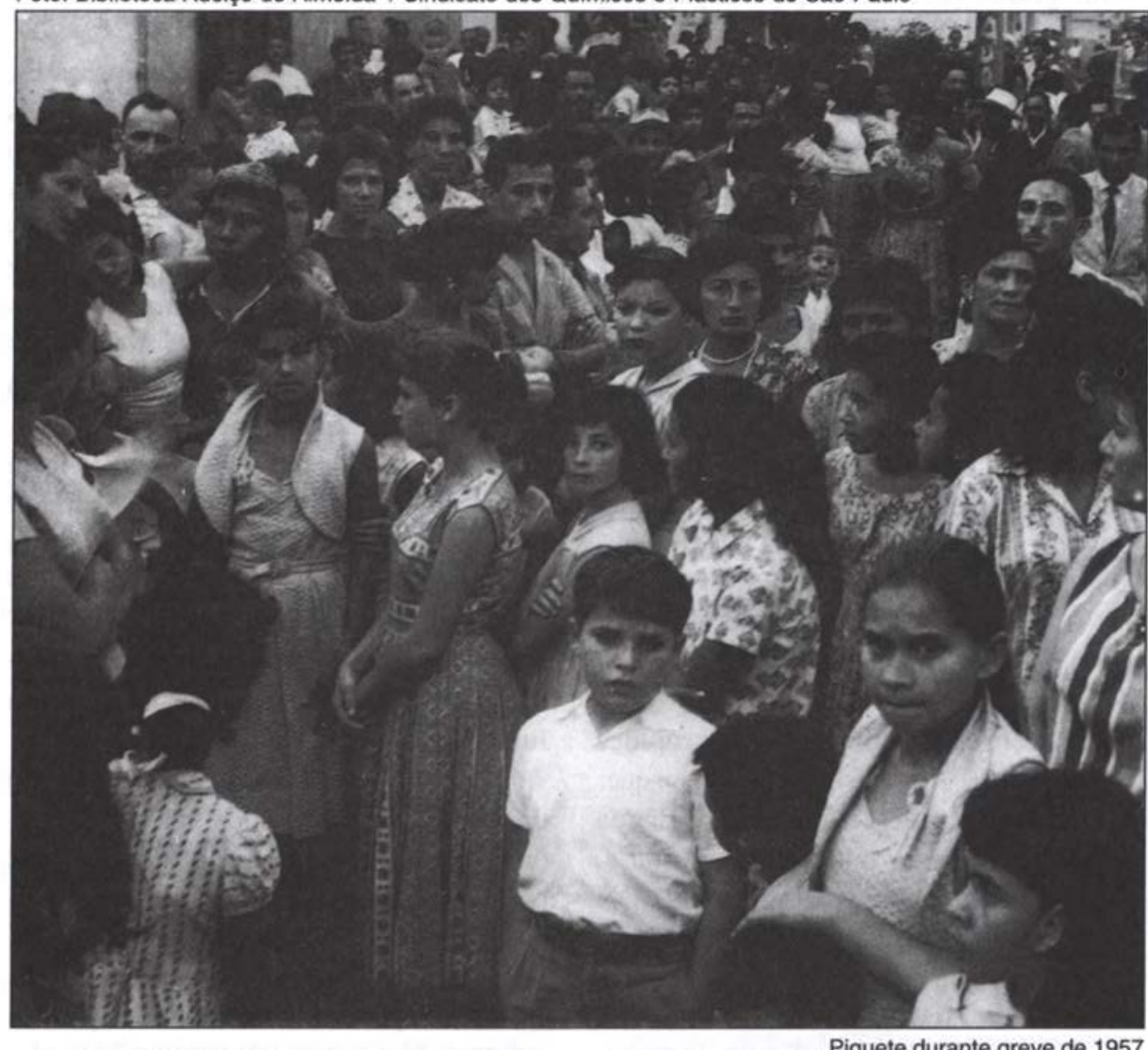

to de pertencer a mesma classe" (Rodrigues, 1966, p.75).

Entretanto, para os trabalhadores da Nitro Química em São Miguel Paulista, as amizades e o conjunto de relações sociais tecidas desde os lugares de origem e ampliadas na fábrica e no bairro eram justamente a base para a elaboração de coesão e solidariedade. Eram essenciais para a formação de uma identidade de classe. As relações pessoais podiam abrir espaço para o questionamento das políticas da empresa consideradas injustas e eram elementos centrais na criação de ações coletivas nos locais de trabalho e moradia. José Ferreira da Silva, líder sindical na região entre o final dos anos 1950 e 1964, destaca a importância dessas relações para a organização dos trabalhadores:

"Naquele tempo, a gente sabia aonde morava o colega de seu departamento. Adoecia o colega, [nós íamos] visitar (...). Iam três, quatro colegas ver como estava o camarada. Era muito solidário. Quando era punido um colega (...) o outro procurava saber o que tinha acontecido. [Foi ai] que eu comecei a assumir. Aquela amizade que nós fomos tendo entre todo mundo fazia a gente trocar idéia um com o outro. Então foi crescendo aquela união, aquela amizade e quando era para reivindicar qualquer coisa a gente [começou] a tirar comissão". 19

Fazer parte das redes sociais desenvolvidas na fábrica e no bairro e compartilhar de referenciais culturais e experiências comuns era fundamental para a formação de lideranças e, por exemplo, possibilitou a construção de legitimidade para a ação sindical na região no período entre 1945 e 1964. Adelço de Almeida, trabalhador da Nitro e presidente do sindicato dos químicos entre 1956 e 1964, acreditava que a sua "procedência de nordestino" lhe dava muito "acesso àquela baianada". "Eles acreditavam muito em mim", explica, "porque eu também ia beber cachaça, dançar forró, fazer farra". ${ }^{20}$

Para além da fábrica, o bairro era um espaço fundamental de articulação das redes sociais e de experiências comuns entre os trabalhadores de São Miguel Paulista. Local de moradia, lazer e trabalho, era no bairro que também se situava 
toda uma gama de relações pessoais com familiares, amigos e conterrâneos que municiava os migrantes com conhecimentos e contatos essenciais para sua sobrevivência. Na vizinhança e vilas, nos bares, pensões e ruas, os trabalhadores de São Miguel conservavam suas relações familiares e de amizades trazidas do Nordeste, criavam novas relações e aprofundavam contatos, muitas vezes iniciados na fábrica. O bairro era, assim, o lugar decisivo para a ressocialização do migrante na cidade e um espaço de trocas de experiências e "produção de cultura" (Hoggart, 1973). ${ }^{21}$

O processo de migração baseado nas redes de contatos e relações pessoais entre os migrantes estimulava a proximidade de moradia entre migrantes de mesmas famílias e regiões. Pesquisas sociológicas realizadas durante os anos 70 destacaram como a proximidade de moradia dos familiares era uma característica importante dos migrantes que se dirigiram para São Paulo nas décadas anteriores. De acordo com um desses levantamentos, quase $70 \%$ dos trabalhadores de baixa renda na cidade possuíam parentes morando no mesmo bairro ou no mesmo quarteirão (Hogan e Berlinck, 1974, p.30). Certamente, esse era o caso de São Miguel Paulista, onde muitas vilas e quarteirões eram quase que completamente habitadas por pessoas procedentes das mesmas cidades e regiões no Nordeste (Tamagno, 1984, p.56).

A greve dos trabalhadores da Nitro Química. em outubro de 1957, foi um momento privilegiado para a percepção da articulação entre as redes sociais dos trabalhadores na fábrica e no bairro. Durante dez dias, as operárias e operários da empresa paralisaram suas atividades reivindicando aumento salarial e melhores condições de trabalho. A greve foi intensamente reprimida pela polícia em seus primeiros dias, sendo registradas várias cenas de violência em toda a região. Apesar disso, o movimento grevista seguiu forte e, com a intermediação do delegado regional do trabalho e do governador Jânio Quadros, conquistou um reajuste de $20 \%$, fato considerado como uma inegável vitória dos trabalhadores (Fontes, 1997).

Em 1957, a greve ultrapassou em muito os limites da empresa. Quase todo o bairro viu-se envolvido no movimento. Piquetes tomavam conta das ruas de São Miguel com o apoio da maioria dos moradores. Os contatos informais e as redes sociais dos trabalhadores cumpriram um papel decisivo na formação dos piquetes e na ampliação da paralisação (Fontes, 1999).

A sub-sede do sindicato dos químicos foi transformada em um verdadeiro 'quartel-general', onde os trabalhadores e a população em geral reuniam-se, organizavam e tomavam decisões em relação à greve. $\mathrm{A}$ solidariedade ao movimento expressavase não apenas na participação em piquetes e assembléias, mas também em ações de auxílio mútuo, como a montagem de uma cozinha e refeitório coletivo que substituiu o restaurante da empresa durante a parede. Era um "entusiasmo danado", relembra Augusto Ferreira Lima, "o sindicato passava a noite toda lotado de gente, (...) não só trabalhador como morador de São Miguel.(...) A greve não foi tão forte com o sindicato como foi com os moradores que ajudaram a fazer a greve". 22

\section{DIVERSIDADES E IDENTIDADES}

Se, por um lado, é evidente a constituição de uma ampla rede social em São Miguel Paulista com grande repercussão política e cultural, convém, por outro, não exagerar a dimensão das relações solidárias entre os trabalhadores do bairro. Embora bastante homogêneo para os padrões da cidade de São Paulo, São Miguel comportava diversas diferenciações internas que periodicamente davam margem para tensões e disputas.

Longe de uma comunidade homogênea e harmoniosa, os trabalhadores de São Miguel Paulista eram um grupo diversificado e complexo. Redes sociais desenvolvidas e as experiências comuns de migração, trabalho e vida no bairro e na cidade criavam, no entanto, bases para linguagens e identidades comuns. Ao longo dos anos 50 , quando o Nordeste virou uma "questão nacional” (Penna, 1992) no imaginário político e social do país, muitos migrantes reapropriaram-se da idéia de uma 'nordestinidade' e associaram sua identidade regional à de trabalhadores.

Os preconceitos, discriminações e dificuldades cotidianas foram respondidos com a criação de um imaginário de valorização da sua capacidade de trabalho. "O nordestino quando ele pega uma coisa para trabalhar ele trabalha mesmo", orgulha-se Afonso José da Silva. A associação do nordestino à idéia de um 'povo trabalhador', que tinha na solidariedade e na disposição para o trabalho duas de suas principais características é recorrente nos vários depoimentos dos migrantes em São Miguel.

Aos muitos que os consideravam simplórios ou ignorantes, os nordestinos rebatiam mostrando sua importância para o desenvolvimento do país. Apropriavam-se da idéia de progresso, destacando o seu papel na história da cidade.

"Naquele tempo (...) paulista queria sombra e água fresca, não trabalhava em três horários. Três horários não era com eles. (...) 'Deixa para a baianada trabalhar', era assim que eles falavam. Então o progresso veio criado pelo homem do norte, que entrava embaixo do sol a sereno, do galho da água de tudo, caía, morria, mas não afastava, tava ali. Trouxe o progresso para São Paulo. Não quero dizer só o homem nordestino não, porque nesse meio do nordestino [também] estava o mineiro. (...) São Paulo de cinqüenta anos para cá foi levantado e erguido a cabeça devido a mão dos nordestinos". ${ }^{23}$

As teses da inadaptação ao trabalho industrial das primeiras gerações de migrantes rurais para São Paulo sustentaram a não identificação desses trabalhadores com a condição operária (Lopes, 1964 e Durham, 1976). Se, por vezes a situação de operário podia não ser desejada, tendo em vista as muitas vezes terríveis condições de trabalho, o autoritarismo das chefias, o extenuante ritmo da produção, a experiência desses migrantes na grande cidade, seus valores culturais e suas redes de relações sociais reforçaram sua identidade enquanto trabalhadores. E era enquanto trabalhadores que os migrantes nordestinos em São Miguel Paulista compartilharam de uma linguagem de classe que reforçava seu papel enquanto dignos produtores de riquezas, construtores de desenvolvimento para a cidade e para o 
país e, portanto, também como cidadãos portadores de direitos.

\section{* Paulo Fontes é Doutorando em História Social/Unicamp.}

\section{NOTAS}

1. Informaçōes retiradas do depoimento de Artur Pinto de Oliveira concedido ao autor em 16/4/1998. Cópias das transcriçōes de todos os depoimentos citados nes. se artigo podem ser encontradas na Biblioteca Adelço de Almeida do Sindicato dos Químicos e Plásticos de São Pauio.

2. Informaçōes retiradas dos depoimentos de Augusto Ferreira Lima concedidos ao autor em 18/5/1998 e 1/6/ 1998.

3. Artigo na revista do Departamento Intersindical de Estudos Sócio-Econômicos (Dieese) calculava que durante os anos 50 , cerca de $30 \%$ dos migrantes em média eram do sexo feminino (Krause, 1962, p.27). De resto, o fenômeno migratório teve semelhante impacto em outros paises da América Latina no mesmo periodo. Fischlowitz, (1959), por exemplo, estima a migracăo de 26 milhōes de trabalhadores rurais para as cidades latino-americanas entre 1945 e 1959.

4. Isso, de forma alguma, significa menosprezar a importância da migração de mineiros (Minas Gerais, durante anos, foi o estado de origem da maior parte dos migrantes para São Paulo e sempre manteve um intenso fluxo de migração) ou de trabalhadores do interior paulista. Além disso, cidades como Brasilia, Rio de Janeiro, Belo Horizonte, Salvador, Recife, Fortaleza e regiōes como o norte do Paraná e a amazônica constituiram-se como importantes receptores de trabalhadores do interior nordestino. Dados sobre as correntes migratórias de vários estados brasileiros para o municipio de São Paulo entre 1900 e 1970 podem ser vistos em Hogan e Berlinck (1974, p.28).

5. Depoimentos de Maria José dos Santos Oliveira concedido ao autor em 26/8/1998 e de Augusto Ferreira Lima.

6. Depoimentos de Irene Ramalho, Geraldo Rodrigues de Freitas (concedidos ao autor em 21/5/1998 e 15/11/ 1994) e Augusto Ferreira Lima.

7. Depoimento de Afonso José da Silva concedido ao autor em 15/10/1997.

8. Depoimento de Oscar Alonso de Oliveira, concedido ao autor em 22/12/94.

9. Depoimento de Gerolino Costa Jacobina concedido ao autor em 15/10/1997.

10. Depoimentos de Augusto Ferreira Lima

11. Depoimentos de Augusto Ferreira Lima e Afonso José da Silva

12. Exemplos de estratégias semelhantes podem ser encontrados na Companhia Docas de Santos ena Fábrica Nacional de Motores no interior fluminense (Silva, 1995 e Ramalho, 1989).

13. Houve um decréscimo das taxas de rotatividade na empresa ao longo dos anos 40 e 50. Em 1939, por exemplo, a empresa tinha uma impressionante taxa anual de rotatividade em torno de 200\%. Em 1957 esse número havia caido para $20 \%$ (Ravaglia, 1988, p.9).

14. Depoimento de José Cecilio Irmão.

15. Arquivos da Companhia Nitro Química Brasileira. Poesia de cordel: A grande explosão da Nitro Química Brasileira, 15/8/1947.

16. O medo de explosōes na fábrica sempre esteve presente em São Miguel Paulista e foi tristemente reafirmado recentemente quando em 15 de novembro de 1997, uma explosão no setor de nitrocelulose causou a morte de um operário, ferimentos em mais quatro trabalhadores e uma série de danos materiais em residências e estabelecimentos comerciais nas imedia- çōes.

17. Depoimento de José Ferreira da Silva concedido ao autor em 8/12/1994.

18. Depoimento de José Cecilio Irmão.

19. Depoimento de José Ferreira da Silva concedido ao autor em 8/12/1994.

20. Depoimento de Adelço de Almeida concedido ao autor e a Hélio da Costa em 25/4/1994.

21. Um dos primeiros a chamar a atenção para o importante papel do bairro na formação de uma cultura dos trabalhadores na Inglaterra foi Richard Hoggart (1973).

22. Depoimentos de Augusto Ferreira Lima

23. Depoimentos de Afonso José da Silva e Augusto Ferreira Lima.

\section{REFERÊNCIAS BIBLIOGRÁFICAS}

ALMEIDA, Vicente Unzer de \& MENDES SOBRINHO,

Octávio Teixeira

(1951) Migraçāo Rural-Urbana: Aspectos da convergência de população do interior e outras localidades para a capital do estado de São Paulo. São Paulo, Secretaria da Agricultura do Estado de Sâo Paulo, p.27.

ANDRADE, Manoel Correia de

(1964) A Terra e o Homem no Nordeste. São Paulo, Brasiliense, p. 99.

ARANTES NETO, Antonio Augusto

(1978) Prođuçāo cultural e revitalização em bairros populares: o caso de São Miguel Paulista. São Paulo, dezembro, p. 12 (mimeo).

AZEVEDO, Aroldo de

(1958) A Cidade de São Paulo-Estudos de Geografia Urbana. Sāo Paulo, Brasiliana, vol. 5

BÓGUS, Maria Lúcia

(1992) "Urbanização e metropolização: o caso de São Paulo". In: BÓGUS, Lúcia Maria e WANDERLEY, Luiz Eduardo (orgs.) A luta pela cidade em São Paulo. São Paulo, Cortez.

DURHAM, Eunice

(1976) A Caminho da Cidade. São Paulo, Perspectiva, p. 63.

FISCHLOWITZ, Estanislau

(1959) Principais problemas da migraçẫo nordestina. Rio de Janeiro: Ministério da Educação e Cultura, p. 26.

FONTES, Paulo

(1997) Trabalhadores e cidadãos. Nitro Química: a fábrica $e$ as lutas operárias nos anos 50 . São Paulo, Annablume e STI Químicas e Plásticas de São Paulo.

FONTES, Paulo

(1999) "Centenas e estopins acesos ao mesmo tempo: A greve dos 400 mil, piquetes e a organização dos trabalhadores em São Paulo (1957)". In: FORTES, Alexandre et AI. Na Luta por Direitos - Estudos recentes em História Social do Trabalho. Campinas, Edunicamp.

HOGAN, Daniel e BERLINCK, Manoel

(1974) "O desenvolvimento econômico do Brasil e as migraçōes internas para São Paulo: uma análise histórica". Campinas: Cadernos do Instituto de Filosofia e Ciências Humanas - Unicamp, p. 28.

HOGGART, Richard

(1973) As utilizaçōes da cultura. Aspectos da vida da classe trabalhadora com especiais referẻncias a publicaçōes e divertimentos. Lisboa. Presença.

HASENBALG, Carlos A.

(1991) A pesquisa sobre migraçōes, urbanização, relaçóes raciais e pobreza no Brasil: 1970-1990.
Rio de Janeiro: luperj, Série Estudos, p. 9 (mimeo.) JATOBÁ, Roniwalter

(1988) Crónicas da vida operária. Săo Paulo, Global.

KOWARICK, Lúcio e BONDUKI, Nabil

(1988) "Espaço urbano e espaço político: do populismo à redemocratizaçāo". In: KOWARICK, Lúcio (org.). As lutas sociais e a cidade-São Paulo: passado e presente. Rio de Janeiro, Paz e Terra.

KRAUSE, Walter Paul

(1962) "Migração e Imigração", Revista de Estudos Sócio-Económicos, p. 27.

LOPES, José Sérgio Leite

(1988) A tecelagem dos conflitos de classe na cidade das chaminés. Săo Paulo, Marco Zero, p.82.

LOPES, Juarez Brandão

(1964) Sociedade Industrial no Brasil. São Paulo, Difel, pp. 57 e 69.

MENEZES, Marilda

(1999) Trajetórias Migratórias na Regiẫo Nordeste do Brasil. Campina Grande, UFPb, p. 7. (mimeo)

NASCIMENTO, Gilberto

(1987) "Sẫo Miguel: o Nordeste em S. Paulo", O Estado de Săo Paulo, 28 de agosto.

PENNA, Maura

(1992) O que faz ser nordestino. Identidades sociais, interesses e o "escândalo" Erundina. São Paulo, Cortez.

RAMALHO, José Ricardo

(1989) Estado-patrão e cultura operária: o caso FNM. Rio de Janeiro, Paz e Terra.

RAVAGLIA, Fábio

(1988) Contribuição à história da Cla. Nitro Química Brasileira: 1935-1985. São Paulo, p. 9 (mimeo).

RODRIGUES, Leóncio Martins

(1966) Conflito industrial e sindicalismo no Brasil. São Paulo, Difel, p. 75.

SADER, Eder

(1988) Quando novos personagens entraram em cena. Rio de Janeiro, Paz e Terra.

SCOTT, R. Parry

(1986) "A lógica migratória camponesa e o capital: o Nordeste brasileiro". In: DUARTE, Renato (org.) Emprego rural e migraçōes na América Latina. Recife, Fundação Joaquim Nabuco e Massangana, p. 88.

SILVA, Fernando Teixeira da

(1995) A carga e a culpa. Os operários das docas de Santos: direitos e cultura de solidariedade. São Paulo. Hucitec, Santos / Prefeitura Municipal de Santos.

TAMAGNO, Liliana

(1984) Nordestinos experiencing São Paulo: time, space and identity in relation to internal migration. Uppsala, Uppsala University, Master thesis, p. 56.

TELLES, Jover

(1981) O movimento sindical no Brasil. São Paulo, Ciências Humanas, p. 31.

THOMSON, Alistair

(1999) "Moving stories: oral history and migration studies", Oral History, vol. 27, n² 1, p. 28.

WEFFORT, Francisco

(1988) "Nordestinos em Sâo Paulo: notas para um estudo sobre cultura nacional e cultura popular". In: VALLE, J. Edênio (org.) A cultura do povo. S. Paulo, Cortez e Instituto de Estudos Especiais, p. 17.

WILLIS, Paul

(1979) "Shop floor culture, masculinity and the wage form". In: CLARKE, John; CRITCHER, Chas. e JOHNSON, Richard (orgs.). Working-class culture. Studies in history and theory. Londres. Hutchinson, p.193. 